\title{
FOTOGRAFIA, INFÂNCIA E EDUCAÇÃO: TESSITURAS DA PRÁTICA DOCENTE NA EDUCAÇÃO INFANTIL
}

\section{PHOTOGRAPHY, CHILDHOOD AND EDUCATION: TEXTURE OF THE TEACHING PRACTICE IN EARLY EDUCATION}

\author{
PEREIRA, Catrine de Moraes \\ catrinedemoraes@gmail.com \\ Rede Estadual de Ensino de Santa Catarina \\ AGOSTINHO, Kátia Adair \\ katia.ufsc@gmail.com \\ UFSC - Universidade Federal de Santa Catarina
}

\begin{abstract}
RESUMO Este artigo - fruto de um Trabalho de Conclusão de Curso do curso de Pedagogia - trata do registro fotográfico e suas possibilidades na prática docente na educação infantil. Nele buscamos refletir sobre as contribuições das ferramentas da ação pedagógica para prática docente, descrevendo as experiências com a fotografia decorridas durante o estágio na educação infantil. Identificando as narrativas e os saberes que se produzem sobre a infância por meio do registro fotográfico, delineamos aspectos que julgamos importantes na constituição do professor. Para tanto, fizemos uma aproximação dos registros fotográficos produzidos no campo de estágio, embasando-os com as teorias referentes à documentação pedagógica e ao registro fotográfico. Compreendemos que o registro fotográfico se fez importante ferramenta da prática docente, pois, assim como a observação e o registro escrito, também contribuiu sistematicamente para uma reflexão sobre a infância e os lugares que as crianças ocupam no meio sócioeducativo. Preocupamo-nos com a apropriação do recurso fotográfico como "meio" e não para "fins" de comprovação das ações/vivências e experiências da prática docente; ressaltando que é necessário educar o olhar, fazendo um distanciamento entre o uso da fotografia no cotidiano e como ferramenta da prática docente, em que se faz produzir sentido à prática educativa. Buscamos tratar das possibilidades de ampliarmos as discussões acerca da utilização da fotografia como um recurso metodológico na prática pedagógica da Educação Infantil, incidindo significativamente nos saberes que elaboramos sobre criança, infância e sua educação.
\end{abstract}

PALAVRAS-CHAVE: Documentação Pedagógica. Educação Infantil. Registro Fotográfico.

ABSTRACT This article deals with the photographic record and their ability in teaching practice in early education, the result of a Working Faculty of Education Course Completion. In it we reflect on the contributions of the tools of pedagogical action for teaching practice, describing the teaching experiences with photography elapsed an internship experience in early childhood education. Identifying the narrative and the knowledge that occur on children through the photographic record thus outlining aspects that we consider important in the constitution of the teacher. To this end, we made an approximation of photographic records produced in the training 
field giving foundation with theories produced regarding pedagogical documentation and photographic record. We understand that the photographic record became an important tool for teaching practice, as well as observation and the written record also consistently contributed to a reflection on childhood and the places that children occupy in the social and educational environment. We care about ownership of the photographic resource as "medium", not "purposes" of evidence of actions / experiences and experiences of teaching practice. Accordingly, pointing out that it is necessary to educate the gaze causing a gap on the relationship of photography use in daily life and use it as a tool in the teaching practice that makes sense to produce educational practice. We seek to address the possibilities of broaden discussions about the use of photography as a methodological resource in the pedagogical practice of early childhood education, focusing significantly on the knowledge we produce about children, childhood and education.

KEYWORDS: Pedagogical Documentation. Early Education. Photographic Register.

\section{INTRODUÇÃO À TEMÁTICA}

As reflexões aqui apresentadas são decorrentes de um Trabalho de Conclusão de Curso, em que discorreremos sobre as contribuições das ferramentas da ação pedagógica para prática docente, com uma aproximação mais densa sobre o registro fotográfico. Nos debruçamos sobre as experiências com a fotografia decorridas de um estágio ${ }^{1}$ na educação infantil do curso de pedagogia, identificando as narrativas e os saberes que se produzem sobre a infância por meio do registro fotográfico, delineando, desta forma, aspectos que julgamos importante na constituição dos saberes sobre a prática pedagógica do professor desta e de outras etapas da educação.

No percurso da pesquisa, ao realizarmos o levantamento bibliográfico da temática, constatamos que as produções sobre a utilização da fotografia na educação infantil são ainda escassas, e por esse motivo fizemos apropriação de outras referências, trazendo para o foco do trabalho, que é pensar a prática pedagógica por meio da fotografia.

Uma das preocupações que acompanharam o estudo foi a da banalização do uso do recurso fotográfico para fins de comprovação das atividades ${ }^{2}$ desenvolvidas pelas crianças ou apenas para uma avaliação da rotina delas e da instituição, em

\footnotetext{
${ }^{1}$ O estágio ocorreu no primeiro semestre de 2014, no Núcleo de Educação Infantil Colônia Z11 (NEI Z11), da rede pública municipal de Florianópolis, situado na Barra da Lagoa.

2 O termo "atividade" não esta se referindo às produções das crianças para um determinado fim, mas no sentido amplo da palavra, ao movimento desses sujeitos em determinado tempo e espaço em que realizam alguma ação, as experiências e vivências no cotidiano institucional.
} 
que fazem uso da fotografia apenas para fins de descrição de uma ação. $\mathrm{Na}$ experiência aqui apresentada buscamos tecer relações entre o registro imagético e registro escrito de modo que pudéssemos somar o conteúdo informante dos mesmos, sem sobreposição ou desvalorização de seus contributos. Tittoni (2010) ajuda-nos a refletir sobre o ato de fotografar, que "implica em escolhas e recortes, dando relevância ao ponto de vista de quem fotografa e a imagem, nesse sentido, deixa de ser somente ilustração de descrições, mas possibilidade de construção a partir de outra forma de escritura" (p.63). Nesse sentido, o registro fotográfico se fez uma importante ferramenta da ação docente, compreendendo que, assim como a observação e o registro escrito, também contribuiu sistematicamente para uma reflexão sobre a infância e os lugares que as crianças ocupam no meio sócioeducativo.

A facilidade de acesso aos equipamentos de produção de imagem (máquinas digitais, celulares, etc) sem dúvida é um fator que contribui, na maioria das vezes, para o uso dessa ferramenta em qualquer ocasião, o que pode acarretar em um distanciamento da intencionalidade pedagógica. As implicações contemporâneas, onde a propagação de informações circulam desenfreadamente nos grandes meios de comunicação, acabam incidindo sobre a ótica do senso comum, na relação que fazem sobre o uso pessoal e o uso profissional dos fins da fotografia.

É necessário, portanto, a problematização da proposta de (re)conhecer a fotografia como um "meio" e não para "fins" de determinada ação. É preciso educar o olhar fazendo um distanciamento sobre essa relação do uso da fotografia no cotidiano e do uso da fotografia como uma ferramenta da prática docente com a qual se produz sentido sobre os fazeres da educação.

\section{DOCUMENTAÇÃO PEDAGÓGICA E AÇÃO DOCENTE}

$O$ que as fotografias nos falam sobre a infância? $O$ que significa compreender o enredo, a cultura, os saberes, os aprendizados da infância pela ótica da fotografia? Para Lima e Nazário (2015), "a fotografia ajuda a registrar detalhes próprios a rituais ou a cultura material dos sujeitos, dos espaços e contexto, mas depende intrinsecamente dos conhecimentos que agregamos sobre as infâncias, 
bem como da disposição que temos para conhecê-las", (p. 08).

O registro fotográfico pode ser o meio pelo qual documentamos informações importantes de situações que nos possibilitam construir uma reflexão da ação educativa. Nesse exercício, o registro fotográfico tem fundamentalmente uma outra forma de "escrever" sobre o vivido, documentar memórias que somam com seu texto estético e sensível para a nossa maior capacidade de compreensão da docência na educação infantil, e para além dela.

Estando o registro fotográfico atrelado à documentação pedagógica, quando tratamos de trazê-las para o contexto da educação infantil, não podemos deixar de destacar a importância das ferramentas da ação pedagógica e as reflexões e teorias que informam. Compreendemos, então, a necessidade de um breve aprofundamento sobre os conceitos elaborados sobre documentação pedagógica, a fim de compreender suas contribuições no exercício de pensar a docência na educação infantil e nas reflexões que tecemos no trabalho.

As contribuições sobre a documentação pedagógica no contexto brasileiro têm seu marco a partir da década de 90, quando estudos realizados na Itália sobre a forma de organização do trabalho docente começa a ganhar visibilidade nas estruturas teóricas e organizacional que dizem respeito à Educação Infantil. O termo "foi inserido na realidade brasileira a partir das experiências italianas, para identificar uma prática docente que possibilita dar visibilidade a várias formas de compreender a criança, as suas realizações e os processos de aprendizagem que ocorrem durante o trabalho educativo" (MENDONÇA, 2009, p.60).

As possibilidades presentes na documentação pedagógica "para a concretização e aperfeiçoamento do trabalho docente, para a ampliação dos espaços de aprendizagem e desenvolvimento do educando, para conhecer os seus modos de ser e agir em espaços coletivos" (MENDONÇA, 2009, p. 60), consideram "a importância da escuta e da observação e vê as crianças como 'competentes' e portadores de 'cem linguagens' " (MARQUES; ALMEIDA, 2012, p.444), tornando-se assim um dos principais meios pelos quais tomamos conhecimento das diferentes ações que perpassam no tempo e nos espaços ocupados por elas.

Em linhas gerais, podemos dizer que a documentação pedagógica é uma forma de sistematização do trabalho docente, que contém a vivência e os 
aprendizados das crianças e do corpo docente, bem como uma forma de expressão da cotidianidade e dos caminhos que nos levam a conhecer cada uma em suas particularidades e em seu convívio social.

Para Marques e Almeida (2012), a documentação pedagógica é ainda a "produção de memória sobre uma experiência, ação que implica a seleção e a organização de diferentes registros coletados durante o processo" (p. 445). As autoras apresentam algumas categorias ou conceitos de diferentes autores sobre a temática, que são relevantes neste trabalho:

Documentação como memória (Benati, 2005; Bresci et al., 2007; Manferrari, 1998; Maselli,1998; Pasquale, 2002; Serra, 1997); documentação e identidade (Manferrari,1998; Maselli, 1998; Pasquale, 2002); documentação e visibilidade do projeto educativo (Specchia, 2001); documentação e avaliação do trabalho (MAVIGLIA, 2000); documentação como comunicação (BENATI, 2005; BRESCl et al.,2007); documentação e pesquisa sobre a ação docente (BORGHI, 1995; BENATI, 2005); documentação como fonte de informação e de conhecimento (BENATI, 2005); documentação e reflexão crítica sobre a prática (SPECCHIA, 2001); documentação e formação contínua (Benati, 2005; Bresci et al., 2007; Manferrari, 1998; Maselli, 1998; Pasquale, 2002; Sacchetto, 2002); documentação e construçãoda identidade profissional (Serra, 1997), (MARQUES; ALMEIRA, 2012, p. 445, grifo nosso)

Gandini e Goldhaber (2002) nos ajudam a pensar sobre as contribuições da documentação para a prática pedagógica quando o objetivo é possibilitar experiências positivas paras as crianças: "A documentação serve para confirmar algo que nós consideramos relevante: dar prova disso e comunicá-lo" (p. 150). Por meio da documentação o professor se coloca como investigador, que, ao observar e registrar de variadas formas, "pretende construir um entendimento que possa ser compartilhado acerca das maneiras como as crianças interagem com o ambiente, como elas se relacionam com os adultos e com outras crianças e como constroem o próprio conhecimento" (GANDINI; GOLDHABER, 2002, p. 151).

Pensamos que a documentação pedagógica é sobretudo uma maneira de ouvir as crianças, de modo a compreendermos o que elas tem a nos dizer sobre a forma como estão vivenciando a infância, como se relacionam com o meio social, como elaboram suas hipóteses sobre as coisas. Assim temos a possibilidade de conhecer seus pontos de vista, seus ensaios, e maior facilidade de elaborar condições favoráveis para a vivência delas no cotidiano educativo. 
Um aspecto importante sobre as possibilidades da documentação pedagógica é sua utilização para fundamentar o planejamento pedagógico. Obviamente, quando tratamos de uma ação educativa, precisamos ter clareza quanto aos objetivos, à forma como serão alcançados, aos recursos necessários, aos espaços e, ainda, sobre quais as experiências que as crianças tem, ou não, com as nossas propostas. Nesse sentido, a documentação pedagógica nos ajuda nos aspectos organizativos do planejamento pedagógico.

Ostetto (2000) em seu texto Planejamento na Educação Infantil, mais que atividade, a criança em foco, alerta para as diversas formas de como conduzimos a prática pedagógica em que, sendo vastas as situações, tende-se a encaminhar o planejamento: baseado em listagem de atividades, em datas comemorativas, em aspectos do desenvolvimento, em temas, em conteúdos organizados por área de conhecimento. A autora ajuda-nos a refletir sobre o planejamento educativo como "um processo de reflexão, pois, mais do que ser um papel preenchido, é atitude e envolve todas as ações e situações do educador no cotidiano do seu trabalho pedagógico" (p.01).

Assim, o planejamento toma forma de orientador da prática pedagógica, em que considera as vivências e experiências das crianças como participantes na construção das propostas pedagógicas. Aqui podemos ressaltar a importância da documentação pedagógica na elaboração do planejamento por meio da observação e do registro.

Gandini e Goldhaber (2002) ainda nos ajudam no sentido de pensar a documentação pedagógica fazendo crítica ao uso dessa para fins de comprovação das "atividades" realizadas no cotidiano da prática docente, ao frisarem que a documentação "não é considerada aqui como uma mera coleta de dados realizada de maneira distante, objetiva e descompromissada. Pelo contrário, ela é vista como uma observação aguçada e uma escuta atenta, registrada conscientemente com sua perspectiva pessoal” ( $p .151$ ). No fazer pedagógico o acesso à novos conhecimentos às crianças "não está na atividade em si, mas na postura do educador, uma vez que não é a atividade em si que ensina, mas a possibilidade de interagir, de trocar experiências e partilhar significados" (OSTETTO, 2000, p. 07).

A documentação pedagógica como prática docente nos convida a narrar 
essas experiências que vivenciamos e tornamos possíveis de serem vivenciadas pelas crianças, e também nos convida a refletir sobre nossa atuação, sobre o que nos constitui verdadeiramente professores dessas crianças pequenas. Ao parar, pensar sobre o que nos constitui como professora, temos questões fundamentais no processo educativo. O que mobiliza as crianças? Mas antes, muito antes... O que mobiliza a ação do professor?

É importante ressaltar que as ferramentas da ação pedagógicas nas mais diversas formas também têm a função socializadora de compartilharmos as experiências vividas com as famílias das crianças e outros sujeitos participantes desse processo. Observamos, registramos, analisamos, refletimos sobre o que se põe diante da nossa vivência com as a crianças, para que possamos conhecê-las verdadeiramente, conhecer as suas diferentes culturas, a fim de romper com a mecanização da prática pedagógica. "A docência convocada a documentar sua ação pedagógica tem como premissa a escuta valorizada enquanto processo dialógico" (MACHADO; RICHTER, 2014, p. 10) em que não só propomos aqui o que nos convém, mas ouvindo as crianças em sua inteireza, a fim de poder ler e refletir criticamente, "de forma individual ou coletiva, sobre as experiências que estamos vivenciando e os projetos que estamos explorando. Isso nos permite construir teorias e hipóteses que não são arbitrárias ou artificialmente impostas pelas crianças" (GANDINI; GOLDHABER 2002, p. 152).

A Pedagogia da Educação Infantil proposta por Rocha (1999), que pensa a criança não mais como um sujeito passivo dos aprendizados que circundam essa etapa da vida, traz implicações que nos instiga a refletir sobre a qualificação do professor e os modos como se organizam para pensar sobre as especificidades da docência na Educação Infantil. É importante rompermos com as práticas cristalizadas, tomando como ponto de partida a necessidade de ter a educação infantil como um espaço de vivências de diferentes culturas, diferentes modos de viver as infâncias que "são sempre contextualizadas em relação ao tempo, ao local e à cultura. Portanto, a maneira como são concebidas diz respeito a entendimentos constituídos histórica e socialmente" (MACHADO; RICHTER, 2014, p. 05), sobretudo tendo a criança como sujeito histórico e de direitos que "por sua vez, estão entre nós, são ativas no seu contexto de vida, agindo no mundo em que 
vivem, incorporando o mundo no qual vivem, influenciando este mundo e construindo significados a partir dele" (MACHADO; RICHTER, 2014, p.05). Desse modo, os espaços institucionais de educação infantil, creches e pré-escolas, devem ser espaços para pensarmos a educação e o cuidado da infância. Não somente um ou outro, mas os dois indissociavelmente.

Partindo dos pressupostos elencados acima, tomamos como objeto de análise as contribuições sobre o registro fotográfico no contexto da educação infantil, para pensarmos sobre a ação docente nessa relação do cuidar-educar.

\section{AS EXPERIÊNCIAS FOTOGRÁFICAS}

Com a fotografia aprendi mais sobre a luz e a sombra e também sobre o silêncio. O silêncio agudo e tumultuado que me habita. O silêncio comigo mesma que preciso escutar enquanto fotografo; o silêncio que não é apatia nem omissão, mas que, ao contrário, pode ser e reverberar uma escuta, um hiato no tempo que o singulariza, que será traduzido numa imagem. (Sonia Vill, 2009).

Os dados de nossa primeira experiência docente no estágio na educação infantil e das primeiras aproximações com o campo da fotografia como recurso pedagógico da ação educativa, como documentação pedagógica, exercitados na observação e registro, nos trouxeram elementos para organizar os espaços internos e externos, captar as formas de expressão e de vivência das crianças no espaço educativo e compartilhar com o coletivo da instituição e familiares as vivências e experiências das crianças e a ação educativa junto às mesmas.

Kossoy (1989) e Barthes (1984) nos ajudam a pensar a fotografia sob três perspectivas: o assunto, o fotógrafo e a tecnologia; ou sobre três práticas "(ou de três emoções, ou de três intenções)" (BARTHES, 1984, p. 20): o fazer, suportar e olhar. É sobre essas perspectivas que introduzimos a fotografia na constituição da docência, em constante formação. Tratamos dos sujeitos e suas relações, sujeitos que são olhados, observados; o fotógrafo (não no sentido formativo da palavra), professores e mediadores dessas relações educativas e das experiências que se constituem na prática docente.

A fotografia como define Kossoy (1989) é uma imagem "registro visual fixo de 
um fragmento do mundo exterior, conjunto de elementos icônicos que compõem o conteúdo: as informações de diferentes naturezas nele gravadas" (p. 41).

\begin{abstract}
$O$ ato do registro, ou o processamento que deu origem a uma representação fotográfica, tem seu desenrolar em um momento histórico específico (caracterizando por um determinado contexto econômico, social, político, religioso, estético etc.); essa fotografia traz em si indicações acerca de sua elaboração material (tecnologia empregada) e nos mostra um fragmento selecionado do real (o assunto registrado) (KOSSOY, 1989, p. 42).
\end{abstract}

Ressaltamos que um dos primeiros aspectos que enfrentamos acerca das discussões aqui apresentadas foram as questões sobre autoria e autorização, um desafio que se faz presente e precisa ser explorado com atenção. As questões levantadas por Kramer (2002) nos ajudam a refletir:

No caso das fotografias de crianças, há que se perguntar: quem autoriza a participação, o nome, a gravação? Quem autoriza a utilização de fotografias? [...] se a autorização quem dá é o adulto, e não a criança, cabe indagar mais uma vez: ela é sujeito da pesquisa? Autoria se relaciona à autorização, à autoridade e à autonomia. Pergunto: como proteger e ao mesmo tempo garantir autorização? (KRAMER, 2002, p. 53).

O trabalho foi norteado pelas questões levantadas acima (com a autorização dos familiares e também das crianças para o uso de suas imagens e nomes reais) trazidas para nosso contexto histórico e social, onde as discussões sobre os direitos das crianças estão evidenciados em documentos legais (LDB, 1996; ECA, 1990) e no campo teórico, principalmente a partir de uma perspectiva sociológica. "A ênfase da sociologia sobre a infância enquanto um grupo social que incide na vida cotidiana e nas estruturas políticas e econômicas vai nos instigando a pensar na forma social da infância” (QVORTRUP, 1994 apud LIMA ; NAZARIO, 2015, p. 03).

Nesse sentido, atentamos para pensarmos sobre essas discussões a respeito dos direitos das crianças, ou das crianças como sujeitos de direitos, em seu sentido ético, relacionados às nossas intenções pedagógicas no que diz respeito ao uso e produção de imagem de crianças. Como mencionado na introdução desse trabalho, há uma preocupação no que diz respeito à propagação e circulação de imagens nas grandes redes de comunicação e interação social-virtual (mas não só), garantida pelo fácil acesso de compartilhamento dessas produções, o que pode culminar, em determinado momento, em um distanciamento de perspectiva pedagógica, quando 
não atentamos para as questões levantadas acima.

Antes da inserção no campo de estágio discorremos sobre os cuidados com a introdução do equipamento nas relações daquele espaço e das formas de conduta ao utilizá-lo. Após os primeiros tempos de aproximação e vivência no NEl, foi possível levar os recursos de registro e observação imagéticos, apresentá-los às crianças, explicando sobre seu funcionamento, os cuidados com o equipamento e a forma de manipulação. Não era possível a todo momento do estágio estar produzindo imagens, embora muitos momentos importantes fossem merecedores desses registros. Voltamos atenção para a importância da observação participativa. A fotografia e a escrita sobre elas foram as principais formas de compreender e aproximar das relações do campo de estágio e da prática docente, principalmente porque permitiu em todo momento fazer recortes sobre as experiências vividas, mas era preciso também ouvir e sentir a voz das crianças.

Nas experiências que tivemos com a fotografia buscamos experimentar diversos modos de refletir sobre o vivido. A "linguagem fotográfica e sua interação com as demais linguagens expressivas constituem um amplo campo de pesquisa e nos aponta outras formas de construção da prática pedagógica e de remoção das barreiras à aprendizagem" (LOPES, 2007, p. 650).

As questões técnicas sobre produção de imagens não foram consideradas nesse trabalho e nessa experiência. Compactuamos com a ideia de Barthes (1984) que "eu tenho a minha disposição apenas duas experiência: a do sujeito olhado e a do sujeito que olha" (p. 21) que reverbera o olhar em uma escuta atenciosa das relações, dos desejos, das intenções e das ações que se manifestam nas interações e trocas de experiências.

Experiência 1: relação das crianças com a natureza 
Figura 1 - "Manuseio" de minhocas

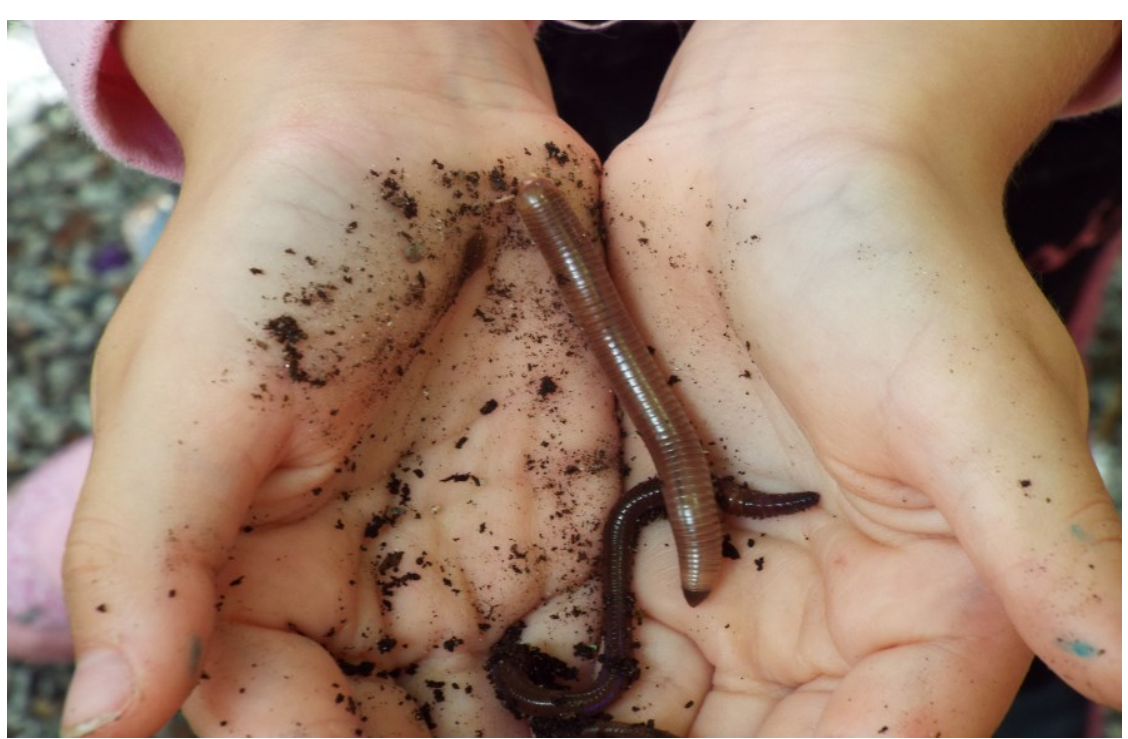

Fonte: Registro de estágio - NEI Colônia Z-11, PEREIRA (2014).

A imagem que mostra as minhocas nas mãos de uma criança não estava apontada para a câmera como pode parecer, a distância da máquina era de uns 10 metros e as mãos apontavam para outra criança, com o intuito de mostrar-lhe que não haveria problemas em tocar nas minhocas. Essa foto foi uma das primeiras a serem produzidas, ela fez parte do registro e contribuiu para que fossemos buscar informações que discorressem das experiências que as crianças estavam tendo naquele momento e quais encaminhamentos pedagógicos as imagens suscitam. $O$ registro segue relatando o seguinte:

"As fotografias ainda me falam muito. No primeiro momento quis registrar a forma como as crianças interagem com a natureza, sem pudor e sem medo. E agora me pergunto, "o que será que elas estavam pensando? Quais perguntas lhes vinham na cabeça? Quais as sensações o contato com um ser vivo diferente lhes causavam? As fotos registradas acima, mostram em um breve momento, a curiosidade das crianças pelos animais, então por que não propor momentos nas quais tenham a oportunidade de vivenciar por mais tempo esse contato com a natureza?" (Registro: 14 e 15/04/2014.)

O uso do registro imagético, seguido do texto escrito, se torna indispensável quando estamos falando de um determinado tempo, espaço e contexto. São as narrativas produzidas por um olhar que está se dispondo a compreender esse contexto a fim de tornar-se mediador das experiências que se fundam no campo. Nesse caso, estamos falando de um tempo que foi formativo e que se delimitou em 
um contexto, por isso se fez necessário seus diálogos e reflexões acerca da produção das imagens.

Kossoy (1989) contribuiu para pensarmos sobre essas questões, afirmando que "as legendas das imagens fotográficas no trabalho científico podem ser constituídas de duas partes: legenda técnica e legenda contextual, tendo ambas a sua devida importância. Vejamos: a legenda técnica deve ser "sumária, objetiva, contendo apenas dados específicos da produção da imagem e sua procedência". Considerando alguns elementos da legenda técnica, temos: o título que se atribui à imagem, local e época em que a imagem foi produzida e informação exata de procedência da imagem. O título pode "se ater ao factual, mas também podem ser jocosos, metafóricos, poéticos, etc., direcionando a leitura do receptor em função de determinada intenção. Ainda destaca que a legenda contextual não deve se constituir em uma mera descrição daquilo que se vê nas imagens:

A contextualização tem por objetivo estabelecer a relação entre o conteúdo da imagem e o contexto em que foi a mesma produzida. Isto significa que essas relações se desenvolvem entre o que vemos na imagem e tudo aquilo que the é externo, o extra quadro espacial e temporal que iremos explorar por meio da pesquisa histórica e iconográfica: o circunscrito de ordem sócio cultural, político, econômico, que envolveu o tema no instante em que se deu o registro, isto é, no momento da sua gênese, suas condições de produção [...] trata-se de trazer à tona dados de abrangência multidisciplinar que constituem os elos e a ligação com o iconográfico: aquilo que vemos na imagem, de forma a produzir sentido (KOSSOY, 1989, p. 106).

Para se fazer compreender a partir desses aspectos do registro é necessário que haja a educação do olhar para aquilo que se pretende com a fotografia. Não há, na prática pedagógica com crianças de pouca idade, possibilidade de se registrar tudo que acontece no entorno das vivências; é preciso fazer o recorte e selecionar de todo o vivido aquilo que produziu algum sentido, "o que se vê não é o dado real, mas aquilo que se consegue captar e interpretar acerca do visto, o que nos é significativo" (PILLAR, 2009, p. 13).

Experiência 2: contos e faz de conta 
Figuras 2 e 3 - Crianças lendo e contando história

Fonte: Registro de estágio - NEI Colônia Z-11, PEREIRA (2014)

As imagens apresentadas são de um momento em que as professoras organizaram o espaço interno da sala dispondo de diversas possibilidades de brincar e interagir.

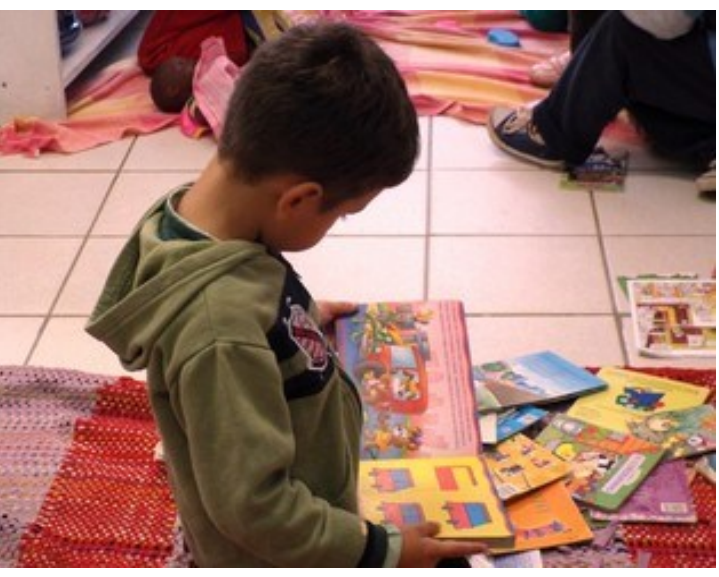

Os registros chamaram atenção para o interesse das crianças pela leitura/histórias. Sem dominarem o código das letras das palavras que ali falavam alguma coisa, o encontro dessas crianças aconteceram no olhar, na leitura das imagens que representavam-Ihes alguma coisa. Arthur parece ler a história pelas imagens, enquanto Raphaela coloca-se no lugar de mediadora da leitura para quem ela conta a história. Ao nos debruçarmos sobre estes registros imagéticos vimos a importância de garantir as experiências narrativas nas creches e pré-escolas,

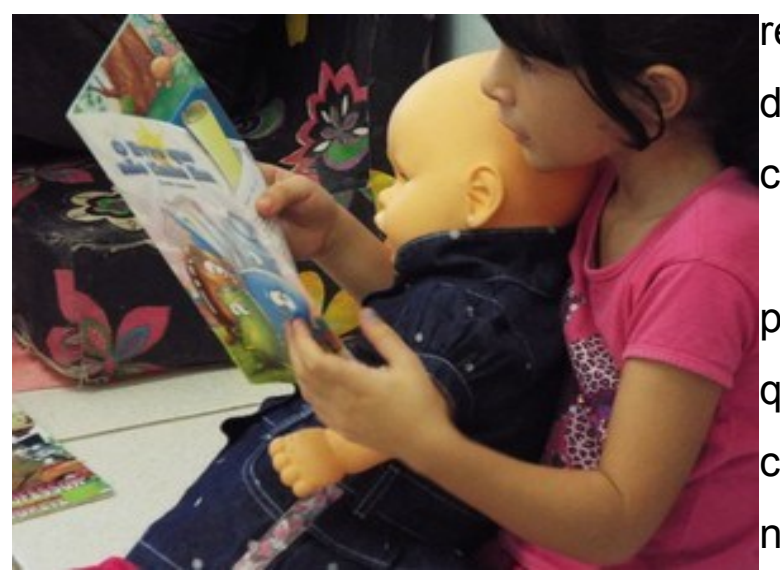
refletindo sobre as contribuições para o desenvolvimento do pensamento lógico das crianças e também da imaginação.

Esses registros e reflexões contribuíram para organizarmos diferentes momentos em que as crianças pudessem estar em contato com a literatura. Nem sempre é possível e necessário que o professor esteja com o grupo inteiro. Assim, a organização em diferentes espaços proporcionou que as vivências pudessem ocorrer com mais fluidez em algumas ocasiões. Com grupos menores, utilizamos o espaço da biblioteca da unidade para aconchegar as crianças na escuta atenciosa do texto literário. Consideramos a organização dos espaços importante para potencializar as vivências e nos preocupamos a todo momento em garantir que nossas contribuições pudessem somar mais experiência e enriquecer as vivências das crianças no sentido de assegurar: 
[...] o contato com diferentes gêneros literários. Isso implica que, na organização de bibliotecas e espaços para os livros nos diferentes lugares da instituição, a seleção de material deve ir além da literatura infantil. Ela pode incluir livros de arte, gibis, jornais, revistas, livros didáticos, livros em braile, álbuns de figurinhas, revistas científicas, livros e outros materiais impressos em línguas estrangeiras, enciclopédia; Oferecer instrumentos para a descoberta do grafismo e da escrita: papéis de diferentes formas e texturas, cadernos, bloquinhos, agendas, canetas, lápis, giz, jogos com letras, carimbos (PREFEITURA MUNICIPAL DE FLORIANÓPOLIS, 2012).

Esse registro nos permitiu pensar um planejamento que pudesse contemplar essas vivências refletindo sobre o tema proposto, enriquecendo nosso olhar a partir das experiências das crianças. O registro imagético seguido do registro onde encontramos as impressões e o olhar do professor sobre a sua prática, configura-se uma decorrência essencial da observação. "No contexto da documentação pedagógica, assume função primordial quando, para além da descrição das realizações infantis, propicia elementos para o professor repensar suas realizações" junto das crianças" (MENDONÇA, 2009, p.68). Pensarmos nossa atuação pedagógica é mais do que propor algo pronto e acabado, mas é refletir sobre as nossas ações a fim de compreender a complexidade das relações humanas para que possamos mediar e contribuir para outras novas experiências que se fundam nessas relações.

A fotografia, desse ponto de vista, como auxiliadora das propostas da prática pedagógica, nos suscita uma preocupação que deve ser pensada com mais delicadeza: a fotografia como ferramenta da prática docente não pode ter seu fim para comprovação das coisas ou produto final dos processos realizados; ela é antes intensificadora dos questionamentos e aprendizados que elaboramos no processo de nos constituirmos professores mediadores da prática educativa. E "ao desencadear questionamentos e impulsionar ações que permitam respondê-los", a documentação, bem como a fotografia como parte dessa documentação, "torna-se elemento importante nos processos da compreensão e aperfeiçoamento da prática pedagógica" (MENDONÇA, 2009, p. 123).

Mendonça (2009) nos tem ajudado a pensar sobre o planejamento pedagógico quando traz em sua tese de doutorado alguns registros que nos permitem ter mais clareza sobre a importância deste para a prática docente e como 
os professores que estão atuando percebem isso nas suas ações. Ao se referir ao ponto de vista das professoras na sua pesquisa, apresenta-nos dois deles, (P1 e P6):

"A documentação é mais do que o registro. Ela envolve o nosso olhar sobre o que aconteceu na sala de aula. A documentação é sistematizada e funciona como base para, a partir dela, podermos dar continuidade ao planejamento, repensando o que fizemos e organizando outras situações para as crianças, conforme as suas necessidades. (P1)O registro é um momento do professor, para ele parar e escrever o que aconteceu em sala de aula. Como foram as discussões, o que aconteceu no desenvolvimento de um projeto, como as crianças reagiram à proposta e como trabalharam. $O$ registro faz parte da documentação e permite que eu possa retomar o que aconteceu e repensar no como vou reconduzir para a próxima etapa" (P6, p. 103).

Percebemos na "fala" desses professores as inúmeras possibilidades de contribuição da documentação pedagógica: falam sobre repensar a prática para replanejar as propostas a partir daquilo que produziu algum sentido nelas, sobre o olhar, sobre o planejamento, sobre as "necessidades" das crianças e como elas reagem às propostas apresentadas.

\section{Experiência 3: Imprevistos previstos}

Figura 4 - Mãos de marinheiro

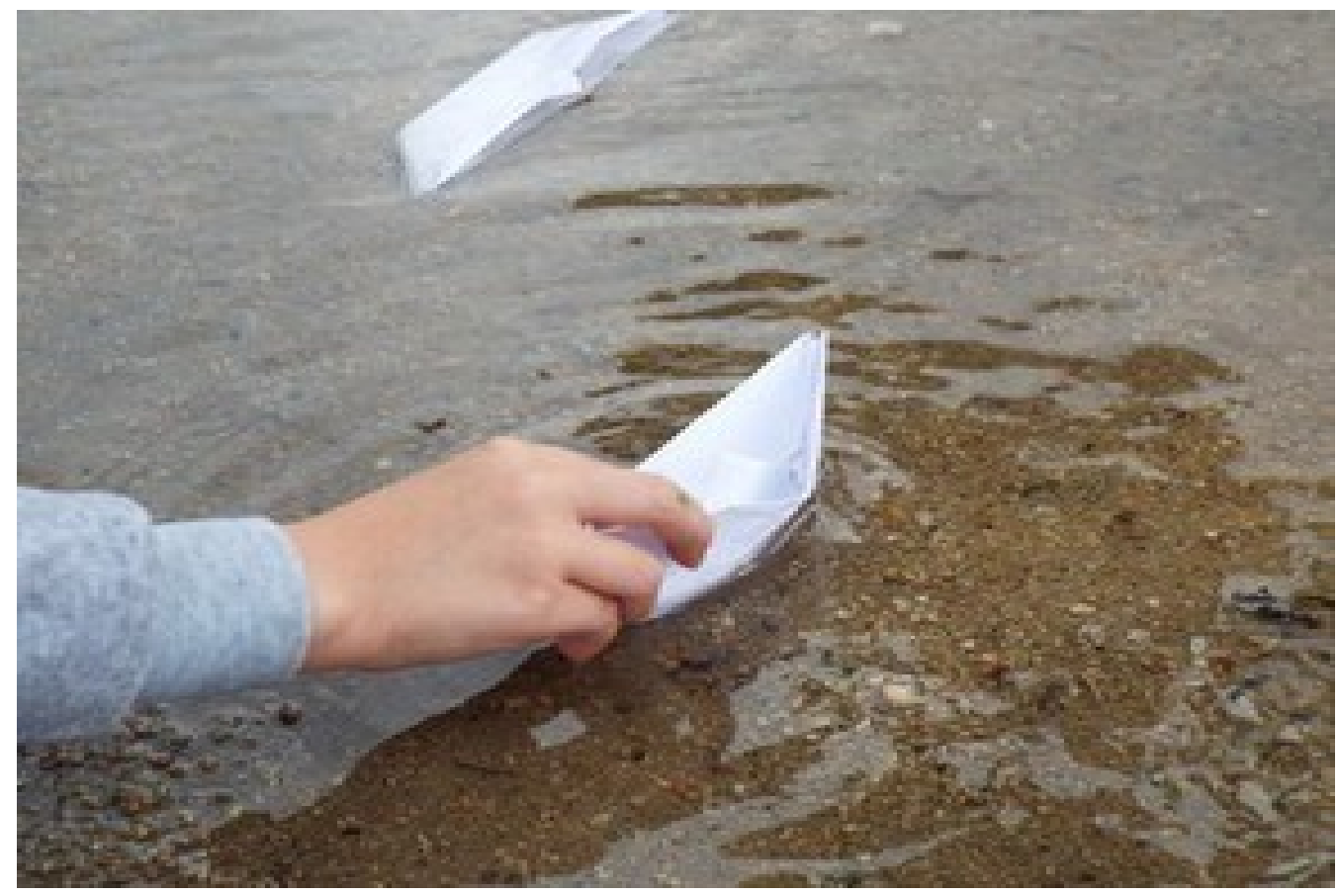

Fonte: Registro de estágio - NEI Colônia Z-11, PEREIRA (2014). 
Essa fotografia fala sobre dois assuntos que consideramos importante abordar aqui. Primeiramente sobre uma experiência que marcou a infância de uma de nós, de tal modo que me permitiu trazê-la, embora em outro tempo, outro espaço e ocupando agora um lugar de professora, não mais de criança na sua infância.

"Era uma tarde chuvosa, eu deveria estar na primeira ou segunda série, como se chamavam na época. Normalmente em dias assim a rotina da escola era a mesma. Todos sentados em filas com cadernos abertos e lápis na mão, tentando ainda desenhar as letras que surgiam aos poucos no quadro negro. Os momentos mais prazerosos daquele dia, habitualmente compreendidos pelas crianças como o momento de brincar - no recreio e na educação física estavam fadados ao escoro duro de uma cadeira de madeira pintada de verde, se não fosse por uma eventualidade nossa professora ter faltado nesse dia.

Entra na sala uma mulher, não tão jovem, de voz firme e segura. Marines era seu nome e até hoje a conheço de andar nas pequenas ruas da cidade em que morava. Começou distribuindo folhas de papel, e em seguida nos ensinou a fazer o barquinho, como esses das fotos. Não era mais caderno, não era mais lápis, não era mais aquela ansiedade por terminar as letras que surgiam e desapareciam naquele quadro verde com rachaduras. Era uma curiosidade para saber o que aconteceriam depois. Enfim a música, que lembro bem até hoje naquela voz firme, segura e um tanto rouca.

'Se está chovendo, vou colocar meu barquinho de papel, pra enxurrada levar.

Se está chovendo, vou colocar Meu barquinho de papel, pra enxurrada levar.

Não sei pra onde vai Nem quando vai parar Talvez pare ali

Talvez chegue ao mar' Uma melodia um tanto melancólica, mas que cativou aquele momento. Fomos levados entre um intervalo e outro de chuva, para brincar com os barquinhos na poça d'água que se formara em frente a cantina da escola. Ali ficamos por muito tempo velejando como marinheiros ao som melancólico que entoava a professora de voz firme. Por acaso, naquele momento de brincadeira eu me recordava do rio turvo que encosta no fundo do terreno da minha casa. Era ali que eu brincava quando era criança. Dentro dos barcos fazia casinha, brincava de ônibus, passava horas jogando pedrinhas no rio para vê-las batendo uma, duas, três vezes na água. Ao certo não sei porque essa experiência marcou minha infância; não sei se há alguma relação das minhas experiências pessoais com àquelas que vivi na escola. O que ficou foi a sensação de uma coisa nova e inesperada, partindo de alguém quase que desconhecida. De uma professora que me cativou e marcou minha infância como uma infância livre". (PEREIRA, 2014).

Depois disso, a fotografia nos instigou a refletir sobre a imprevisibilidade que habita a relação educativa e nela a oportunidade de que seja preenchida pela imaginação das crianças - o que podemos planejar a partir daquilo que temos? 0 
estágio acontecia no período da tarde, mas nesse dia o parque ainda tinha resquícios de uma manhã chuvosa, que formara as tais poças d'água. No mesmo instante que a experiência relatada era lembrada, pensávamos em oportunizar às crianças essa vivência. Uma vontade imensa de tornar um dia cinzento em uma grande tarde de aventuras.

As experiências relatadas aqui nos fizeram pensar a prática docente sobre dois vieses que podem estar entrecruzados, o imprevisto e a imaginação. $O$ imprevisto, inusitado e surpreendente, muitas vezes oportuniza a entrega, tanto por nós professoras quanto para as crianças. O imprevisto é previsto porque está em consonância com a imaginação, é o espaço em aberto. E sobre a imaginação nesse universo, Girardello (2011) diz que "é para as crianças um espaço de liberdade e de decolagem em direção ao possível, quer realizável ou não. A imaginação da criança move-se junto, comove-se - com o novo que ela vê por todo o lado no mundo" (p.76). As fotografias nos falam que, sim, é possível viver e pulsar, aprender e experienciar, mantendo em atenção e aberto espaço e tempo para a fruição. Porque elas estão brincando, mas estão elaborando conhecimento sobre as coisas, estão brincando e em suas brincadeiras imaginando algo que está relacionado ao mundo real.

Ressaltamos ainda sobre o uso e produção de imagens como expressão e vivência da dimensão estética, pelo simples fato de apreciar o que é belo na fotografia, pensar a fotografia como uma manifestação da arte e que deve ocupar seu espaço nos ambientes em que as crianças circulam, dando visibilidade as diferentes manifestações culturais por meio do registro imagético.

As possibilidades se estendem não apenas em utilizar as fotografias produzidas por nós professores, mas também oportunizar que as próprias crianças tenham esse contato com a produção e leitura de imagens. Trata-se de utilizar a fotografia não apenas como recurso didático e metodológico para explicação das experiências vividas. Nesse sentido, a relevância de focarmos o olhar para as produções infantis em suas dimensões estéticas se consolida em planejar ações que tornem tais experiências prazerosas, rompendo com a didatização e a mecanização das experiências estéticas no universo infantil. Oliveira (2008) nos diz que "a lógica estética adultocêntrica tem por finalidade utilizar desses meios como um produto 
final, entendidos como uma forma de registro, comprovação de atividades que as crianças realizam nas creches e pré-escola", desta forma inibindo a fruição estética e o processo imaginativo. Romper com essa lógica nos possibilita ampliar o repertório de experiências com a linguagem visual, contribuindo significativamente "para a mobilização do processo criador dos alunos e professores e a produção de narrativas" (LOPES, 2007, p. 650).

\section{CONSIDERAÇÕES FINAIS}

O estudo da experiência docente constatou o quanto é importante estar em constante movimento e atuação, não somente na prática mas no diálogo constante com as produções teóricas que nos ajudam e nos fortalecem enquanto seres pensantes e reflexivos de uma prática educativa. Um hiato de tempo e tudo parece escorrer entre os dedos da mão. O Trabalho de Conclusão de Curso, do qual apresentamos um recorte, nos proporcionou grande satisfação e alegria, pois nele podemos perceber as inúmeras possibilidades de fazer da docência algo prazeroso e que nos mobiliza a pensar nas diversas formas de participação na formação humana.

Ao refletir sobre o papel docente a partir dos aspectos levantados no trabalho - documentação pedagógica e registro fotográfico de uma experiência de estágio docente -, manteremos um questionamento sempre presente: $O$ que mobiliza a prática educativa? Certamente as respostas são inúmeras, e buscamos algumas respostas possíveis nos meandros da produção do registro fotográfico, é a partir dele que temos pensado e refletido cotidianamente sobre o nosso papel de professoras.

Reiteramos a necessidade de análise dos registros imagéticos em conjunto com o registro escrito, a fim de contextualizar a fotografia e nossa leitura acerca do vivido. Nesse contexto, também refletimos sobre educar o olhar para aquilo que produz sentido à nossa prática educativa. Os registros contribuíram para pensarmos sobre a forma de organização dos espaços e de elaborar planejamentos da prática pedagógica que abarquem as vivências e experiências das crianças.

O registro fotográfico como suporte material que o professor tem em mãos 
para retornar, rememorar e apurar o olhar, refletir sobre o vivido, neste reencontro através da fotografia como o seu fazer pedagógico intensifica e complexifica questionamentos e aprendizados que elaboramos no processo de nos constituirmos professores.

Nos cotidianos das relações e dos acontecimentos no entorno das nossas vivências na educação infantil vimos a importância da imaginação nas imprevisibilidades que nos ocorrem, salientando a importância da brincadeira e da imaginação na aprendizagem e vivência sobre as coisas do mundo. O registro fotográfico apresenta-se como um recurso importante para compreendermos mais os fatos que ocorrem no cotidiano institucional, para dar visibilidade à expressividade das crianças, seus pontos de vista, e assim aumentar nossa capacidade de conhecê-las e pensar a sua educação.

Ainda ficam alguns questionamentos como convite para seguirmos pensando coletivamente o que nos constitui professores da infância: Como as fotografias nos falam sobre essas imprevisibilidades do cotidiano? Como as fotografias oportunizam a manifestação artística e vivência estética? É possível pensar ou escrever por imagens?

\section{CATRINE DE MORAES PEREIRA}

Graduada em Pedagogia. Integrante do grupo de pesquisa NICA (Núcleo de Infância, Comunicação, Cultura e Arte).

\section{KÁTIA ADAIR AGOSTINHO}

Doutora em Estudos da Criança pela Universidade do Minho/Portugal. Pesquisadora do NUPEIN - Núcleo de Estudos e Pesquisas da Educação na Pequena Infância (UFSC). Coordenadora Adjunta do curso Docência em Educação Infantil - Extensão NUPEIN/CED/UFSC.

\section{REFERÊNCIAS}

BARTHES, R. A câmara clara: notas sobre a fotografia. 3. ed. Rio de Janeiro: Nova Fronteira, 1984. 185p.

BRASIL. Ministério da Educação. Lei de Diretrizes e Bases da Educação Nacional. Brasília: Ministério da Educação, 1996. 
BRASIL. Lei $n^{\circ}$ 8.069, de 13 de julho de 1990. Dispõe sobre o Estatuto da Criança e do Adolescente e dá outras providências. Diário Oficial da União, Brasília, DF, 16 jul. 1990.

GANDINI, L; GOLDHABER, J. Duas Reflexões sobre a Documentação. In: GANDINI, L; EDWARDS, C (orgs). Bambini: a abordagem italiana à educação infantil. Porto Alegre: ArtMed, 2002. p. 150-169.

GIRARDELLO, G. Imaginação: arte e ciência na infância. Campinas: Pró-posições, 2011.

KOSSOY, B. Fotografia e História. São Paulo: Ática, 1989.

KRAMER, S. Autoria e autorização: questões éticas nas pesquisas com crianças. Cadernos de Pesquisa, 2002, n. 116, p. 41-59.

LIMA, P. M.; NAZÁRIO, R. Sobre a Luz do diafragma: a atribuição da fotografia na pesquisa com crianças. No prelo, 2015.

LOPES, A. E. Animação de imagens: uma nova interface entre a fotografia e os meios digitais na produção de narrativas. Florianópolis: ANPAP - $16^{\circ}$ Encontro da Associação Nacional de Pesquisadores de Artes Plásticas Dinâmicas Epistemológicas em Artes Visuais, 2007. Disponível em: HYPERLINK "http://anpap.org.br/anais/2007/2007/artigos/065.pdf"http://anpap.org.br/anais/2007/2 007/artigos/065.pdf. Acesso em: 28 de Junh. 2015.

MACHADO, N. S; RICHTER, S. R. S. Documentação pedagógica na Educação Infantil: por uma Docência Narrativa. Florianópolis: X ANPED SUL, 2014.

MARQUES, A. C. T. L.; ALMEIDA, M. I. A documentação pedagógica na abordagem italiana: apontamentos a partir de pesquisa bibliográfica. Revista Diálogo

Educacional, Porto Alegre, v. 12, n. 36, p. 441-458. 2012.

MENDONÇA, C. N. de. A documentação pedagógica como processo de investigação e reflexão na educação infantil [Tese], Marília: Universidade Estadual Paulista "Júlio de Mesquita Filho", 2009. 135 p.

OLIVEIRA, A.M.R. Escultura \& imaginação infantil: um mar de histórias sem fim. [Tese] Florianópolis: Universidade Federal de Santa Catarina, 2008. 277p, Programa de Pós-Graduação em Educação, Universidade Federal de Santa Catarina, Florianópolis 2008.

OSTETTO, L. E. Planejamento na Educação Infantil: mais que a atividade, a criança em foco. In: OSTETO, L. E. (org). Encontros e encantamentos: Partilhando experiências de estágios. Campinas, SP: Papirus, 2000, p.175-200.

PILLAR, A. D. Leitura e Releitura. In: PILLAR, A. D (org.). A educação do olhar no ensino das artes. Porto Alegre: Editora Mediação, 2009. 
PREFEITURA MUNICIPAL DE FLORIANÓPOLIS, Secretaria Municipal de Educação. Orientações curriculares para Educação Infantil da rede municipal de ensino de Florianópolis. Florianópolis: Prelo Gráfica e Editora Ltda, 2012. 264 p.

ROCHA, E. A. C. A pesquisa em educação infantil no Brasil: trajetória recente e perspectivas de consolidação de uma pedagogia [Tese]. Florianópolis: UFSC Centro de Ciências da Educação, 1999. 162 p. (Teses NUP 2). ISBN 85-328-0171-4.

TITTONI, J.; et al. A fotografia na pesquisa acadêmica: sobre visibilidades e possibilidades de conhecer. Informática na Educação: teoria \& prática, Porto Alegre, v. 13, n. 1, p. 59-66, jan./jun. 2010.

VILL, S. Ensaiando o olhar: o sentido da infância a partir de fotografias produzidas por crianças. Florianópolis: Universidade Federal de Santa Catarina, 2009. Dissertação de Mestrado. Programa de Pós Graduação em Educação. Universidade Federal de Santa Catarina. 